\title{
Sharing Experiences with Social Mobile Media
}

\author{
Jari Multisilta ${ }^{(1,2}$ \\ 1) Visiting Fellow \\ Nokia Research Center \\ Visiokatu 1, 33720 Tampere, Finland \\ +358504871707 \\ 2) Professor \\ Tampere University of Technology \\ PO Box 300, 28101 Pori, Finland \\ +358408262747 \\ jari.multisilta@tut.fi
}

\author{
Marcelo Milrad \\ Professor \\ Växjö University \\ PG Vejdes 6, 35195, Växjö, Sweden \\ +46733969574 \\ marcelo.milrad@vxu.se
}

\begin{abstract}
In this workshop we are interested in usability, context and user practices related to uses of social mobile media for sharing human experiences. There is a growing trend pointing to life publishing and life logging using mobile devices. Users are sharing their experiences and their life with friends in real-time by posting blog notes, images and video clips from their phones to social media services. In addition, people are tagging content either by manually or using sensory data with their phones. An interesting question to be asked is; How users are experiencing these applications and what issues make them to be successfully adopted? This workshop will offer an interdisciplinary discussion forum for both practitioners and academics interested in conceptualizing, designing and evaluating emerging social mobile media concepts and applications. The workshop, through a series of interactive presentations, will facilitate discussions aiming at identify and summarize main theoretical and interaction design concerns related to the increasing use of social mobile media in a variety of settings. The main goal of the workshop is to find out ideas that suggest promising directions for future research on social mobile media.
\end{abstract}

\section{Categories and Subject Descriptors}

H.5.2 [User Interfaces]: Evaluation/methodology, Human Factors, Theory. Theory and Methods, User-centered design; H.5.3 [Group and Organization Interfaces]: Computersupported collaborative work; Web based interaction;

\section{General Terms}

Design, Experimentation.

\section{Keywords}

Social media, mobile, design, evaluation, experiments, experiences, usability, context, life publishing, life-logging, sharing
Copyright is held by the author/owner(s). MobileHCI09, September 15 - 18, 2009, Bonn, Germany. ACM 978-1-60558-281-8/09/09.

\section{INTRODUCTION}

Current advancements in wireless and sensors technologies combined with the rapid adoption of sophisticated mobile multimedia devices and applications have created new social software tools for people to connect and interact; therefore changing the ways we communicate and collaborate. Mobile users are now creating and sharing increasing amounts of media content, thus generating large volumes of rich data sets. This latest fact indicates that mobile social media is about to become an integral component of distributed environments and applications of the mobile web. Currently, many applications of mobile social media can be found in areas such as leisure and entertainment. However, recent developments indicate that social media is starting to be adopted by companies as well [14]. In addition to life publishing, life-logging is also finding its way to mobile phones [16] with applications such as Nokia SportsTracker [1].

The aim of this workshop is to introduce, present and discuss concepts and applications related to current research efforts in the emerging field of social mobile media.

\section{BACKGROUND AND DEFINITIONS}

Social networking and networks have become a major new communication and networking mechanism in various fields including among others entertainment, education and business. Several large social networking tools and sites can be found in the web including many blogging sites such as Blogger, image and video sharing sites such as YouTube, Facebook, Flickr, and Kyte and mobile oriented social media applications for microblogging [4] such as Jaiku and Twitter. People are now sharing their personal media including photos and videos among friends or more publicly with unknown users. Östman has characterized this phenomenon as life publishing, which includes all the means used by people willing to publish events of their lives in the Internet [17].

One of the first reported studies about the use of camera phones was published by Okabe and Ito [8]. These authors claim that "unlike the traditional camera, the camera phone is an intimate and ubiquitous presence that invites a new kind of personal awareness, a persistent alertness to the visually newsworthy that makes amateur photojournalists out of its users." Van House \& Davis [9] have defined four higher-order social uses of personal photography, namely creating and maintaining social relationships; constructing personal and group memory; selfpresentation; and self-expression. In addition, based on their research they also found three interpretations of the usage of 
camera phones: as memory-capture devices, communicative devices, and expressive devices. Thus, we would like to suggest and extend these social uses and camera phone roles by claiming that these notions can be applied also in a broader context, namely social mobile media.

Social media is a combination of people, technologies, new rich digital content and practices that enables users to share their experiences with other users, thus building a shared meaning among communities. In fact, experiences are mediated by technologies as a form of content; i.e. the real world experience is reflected as a blog note, a set of images or video clips. Mobility adds the freedom of time and place - A user can share his/her experiences from wherever there is reasonable network access. In addition, social mobile media may support the automatic gathering of contextual information, for example by adding geotags to images.

\section{CURRENT RESEARCH EFFORTS}

The amount of research efforts reporting various uses of social mobile media to support sharing experiences has been rapidly evolving in the last few years. For example, Koskinen [7] have studied how people use camera phones in communication and action. Koskinen studies "technologies that enable people to capture, send, and receive photographs, sounds and sometimes video" from an ethnomethodological standpoint. The concept of Ethnomethodology was first introduced by Harold Garfinkel [3] in the late sixties. This particular discipline aims at describing how people produce orderly social conduct.

Mobile video as such has not yet been studied extensively. Jokela, Karukka and Mäkelä [5] have designed video editing tools to be used on a mobile phone. Based on their study, video editing on mobile devices is feasible despite of small displays and limited input devices. In addition, Jokela, et al. [5] suggest that there is a true need for a video editing application on mobile devices. Multisilta and Mäenpää [11] presented a social mobile media service, where users can upload video clips they have taken with mobile phones, and create stories using either their own clips or clips from the community. Their study showed that, it is possible to let several authors to compose a video story or produce a common storyline shooting video clips independently from different place in different time. They also showed that this kind of social mobile media service can be used in mediating experiences. Multisilta has also presented a design framework for social mobile media applications [12].

Reponen, Huuskonen and Mihalic [15] have studied how videophones will affect the way people perceive video-recording, in terms of privacy, transparency, and the notion of context. They have defined primary and secondary contexts for modeling and analyzing different mobile video usage situations. They define the primary context to be the "immediate surroundings; a situation where people can communicate in shared time and space without help of technical devices" and the secondary context to be "any (remote) situation where the recorded video is used" [15].

Cesar, Bulterman, Geerts, Jansen, Knoche and Seager [2] claim that current media sharing systems provide only the limited support for manipulating, customizing and enhancing the media. It seems in systems they have studied users are expected to consume media and not socially interact with it. Cesar et al. have designed an architecture and implementation of a social approach to viewing and sharing media. These kinds of services are needed because media consumption is an inherently social activity, serving to communicate ideas and emotions across communities [2].

According to McCarty and Wright [10], interacting with technology involves us emotionally, intellectually, and physically. In the case of social mobile media, interaction with technology is related to sharing experiences among people and supported by technology. Accordingly, the role of technology can be defined as a mediator. Technology is mediating our experiences with others while being an experience by itself. McCarthy and Wright claim that we have to "interpret the relationship between people and technology in terms of life felt and the feeling or emotional quality of action and interaction" [10]. We can understand these concepts when we think of different brands - people like to belong to a certain group by owning certain products or using certain services.

Based on Wikipedia's definition, experience means "to observe certain events; undergo a certain feeling or process; or perform certain actions that may alter one or contribute to one's knowledge, opinions, or skills". Felt experience is one's interpretation of the experience [10]. For example, We can express our experiences by telling about them, drawing, taking photos etc. Klastrup [6] defines a mobile story or narration to be a structured and mediated presentation of experiences with recognizable beginning and end. So, the use of technology as a mean of sharing our experiences with our family, friends or communities is called a shared felt experience.

\section{GOALS OF THE WORKSHOP}

In this workshop we are interested in usability, context and user experiences aspects connected to the use of social mobile media applications. The usability of social mobile media applications may depend on many issues, including the end user device and possible sensors (such as GPS devices, heart rate monitors etc connecting to the mobile phone), and the available network connection. There is a growing trend pointing to life publishing and life logging using mobile devices. An interesting question to be asked is; how users are experiencing these applications and what issues make them to be successfully adopted? Another dimension is the notion of context and its relation to the design and implementation of social mobile media applications. How do we bring different aspects of context (physical, social, etc) into the design of social mobile media applications? Is it possible to automate personal and contextual tagging of media, places and objects? Can we enhance the physical context and presence in to the social media using mobile tools? These issues should be studied by looking at four dimensions of experience: real-world experience, felt experience, user experience and mediated experience.

The workshop invites full papers and/or work in progress contributions on all themes related to the questions described above. Submitted papers will be evaluated based on significance, originality, clarity of ideas and concepts and technical quality. They should clearly establish their research contribution to the field, its relevance to this particular research area, and its relation to prior research.

Accepted papers will be published as workshop proceedings in the Tampere University of Technology publication series. The 
workshop materials, together with a summary of discussions, will be published on the web after the workshop.

\section{ORGANIZERS}

Jari Multisilta is the professor of multimedia in Tampere University of Technology, Information Technology at Pori, Finland and a Visiting Fellow at Nokia Research Center, Tampere, Finland. He got his M. Sc from the University of Tampere in 1992 in Mathematics and his Dr. Tech. at Tampere University of Technology in 1996. The title of his doctoral thesis was "Hypermedia Learning Environment for Mathematics". Prof. Multisilta has studied learning and modern communication and information technologies and has taken part in several research projects on this area. Currently, his research interests include networked and mobile learning, and mobile social media. Professor Multisilta has published over 80 international conference papers and journal articles on his research area. At Nokia Research Center he is doing research on video applications of mobile social media. Multisilta has visited University of Stanford, H-STAR Institute on 2007 and 2008 and was a coorganizer of a Social Mobile Media Workshop The Summer Institute at Wallenberg Hall at Stanford University on August 2008.

Marcelo Milrad is a Professor of Media Technology at the Department of Computer Science, School of Mathematics and Systems Engineering, at Växjö University in Sweden. He is also the director of the Center for Learning and Knowledge Technologies (CeLeKT). His current research interests include the design of collaborative tools and social media to support collaborative discovery learning as well as the development of mobile and wireless applications to support collaborative learning. Dr Milrad teaches undergraduate courses in media technology and computer science with a special focus on XML, web 2.0 and mobile technologies. He teaches also doctoral courses in the field of Technology Enhanced Learning. Professor Milrad has published over 100 articles in international journals, refereed conferences, books and technical reports. He has also been presenting and giving lectures about his work in more than 30 countries worldwide. During the last 15 years, Dr. Milrad has been directly involved in the design and development of multimedia based learning environments both in schools, universities and in industrial settings.

\section{REFERENCES}

[1] Ahtinen, A. 2008. Wellness applications -- ui design to support long-term usage motivation. In CHI '08 Extended Abstracts on Human Factors in Computing Systems (Florence, Italy, April 05 - 10, 2008). CHI '08. ACM, New York, NY, 2669-2672.

[2] Cesar, P., Bulterman, D. C., Geerts, D., Jansen, J., Knoche, H., and Seager, W. 2008. Enhancing social sharing of videos: fragment, annotate, enrich, and share. In Proceeding of the 16th ACM international Conference on Multimedia (Vancouver, British Columbia, Canada, October 26 - 31, 2008). MM '08. ACM, New York, NY, 11-20.

[3] Garfinkel H. 1967. Studies in Ethnomethodology. Englewood Cliffs, NJ: Prentice-Hall.

[4] Java, A., Song, X., Finin, T., and Tseng, B. 2007. Why we twitter: understanding microblogging usage and communities. In Proceedings of the 9th WebKDD and 1st
SNA-KDD 2007 Workshop on Web Mining and Social Network Analysis (San Jose, California, August 12 - 12, 2007). WebKDD/SNA-KDD '07. ACM, New York, NY, 5665.

[5] Jokela T., Karukka M., and Mäkelä K. 2007. Mobile Video Editor: Design and Evaluation. In J. Jacko (ed.): HumanComputer Interaction, Part II, HCI 2008, LNCS 4551, Springer-Verlag Berlin Heidelberg, pp. 344-353.

[6] Klastrup L. 2007. Telling \& Sharing? Understanding Mobile Stories \& Future of Narratives. pertDAC 2007 The Future of Digital Media Culture. 7th International Digital Arts and Culture Conference, Perth, Australia 15-18th September.

[7] Koskinen I. K. 2007. Mobile Multimedia in Action. Transactions Publishers, New Brunswick, London.

[8] Okabe D., and Ito M. 2004. Camera phones changing the definition of picture-worthy. Japan Media Review. Annenberg School for Communication, USC, http://ojr.org/japan/wireless/1062208524.php [11.05.2008].

[9] Van House, N., and Davis M. 2005. The Social Life of Cameraphone Images. In Proceedings of the Pervasive Image Capture and Sharing: New Social Practices and Implications for Technology Workshop (PICS 2005) at the Seventh International Conference on Ubiquitous Computing (UbiComp 2005).

[10] McCarthy J. \& Wright P. 2004. Technology as Experience. The MIT Press, Cambridge, Massachusetts, London, England.

[11] Multisilta J., and Mäenpää M. 2008. Mobile Video Stories. In Proceedings of the 3rd International Conference on Digital interactive Media in Entertainment and Arts (Athens, Greece, September 10 - 12, 2008). DIMEA '08, vol. 349. ACM, New York, NY, 401-406.

[12] Multisilta J. 2008. Designing for Mobile Social Media. Proceedings of The NordiCHI'08 Workshops New Approaches to Requirements Elicitation \& How Can HCI Improve Social Media Development? Tapir, Trondheim, November 2008, ISBN 978-82-519-2394-1.

[13] Pacey A. 1999. Meaning in Technology. The MIT Press, Cambridge, Massachusetts, London, England.

[14] Postman J. 2009. SocialCorp. Social Media Goes Corporate. New Riders, Berkeley, USA.

[15] Reponen E., Huuskonen P., and Mihalic K. 2008. Primary and secondary context in mobile video communication. Personal Ubiquitous Computing, 12:281-288.

[16] Sellen, A. J., Fogg, A., Aitken, M., Hodges, S., Rother, C., and Wood, K. 2007. Do life-logging technologies support memory for the past?: an experimental study using sensecam. In Proceedings of the SIGCHI Conference on Human Factors in Computing Systems (San Jose, California, USA, April 28 May 03, 2007). CHI '07. ACM, New York, NY, 81-90.

[17] Östman, S. 2008. Elämäjulkaiseminen omaelämäkerrallisten traditioiden kuopus (Life publishing youngest child of autobiographical traditions). ELORE, vol. $15-2 / 2008$. Suomen Kansantietouden Tutkijain Seura ry. [http://www.elore.fi /arkisto/2_08/ost2_08.pdf] (in Finnish) 